\title{
Pareceres descritivos no Projeto Amora do Colégio de Aplicação - UFRGS: o que estudantes e pais têm a dizer?
}

\author{
Bruna Castilhos \\ Rosane Nunes Garcia ** \\ Stela Maris Vaucher Farias ${ }^{* * *}$ \\ Rosália Procasko Lacerda ${ }^{* * *}$
}

Resumo: Para alguns autores, o parecer descritivo é a forma de registro de avaliação mais qualificada para descrever os processos de aprendizagem dos estudantes. No entanto, outros afirmam que, assim, podem ser produzidos relatos subjetivos e sem significado. Os objetivos deste trabalho foram: verificar os níveis de compreensão que pais e estudantes possuem a respeito do parecer elaborado pelos professores da referida instituição de ensino; a aceitação do conteúdo do parecer no que diz respeito aos aspectos atitudinais, procedimentais e de desenvolvimento cognitivo dos estudantes. Foram utilizadas análises qualitativas nos questionários realizados e nas análises quantitativas dos pareceres. Os resultados mostraram que o parecer tem grande aceitação por parte de pais e de estudantes, em relação às observações cognitivas, atitudinais e procedimentais as quais são abordadas em equilíbrio e que os responsáveis pelos estudantes parecem

* Licenciada em Ciências Biológicas pela UFRGS, Porto Alegre, Brasil.

* Professora pesquisadora do Departamento de Ciências Exatas e da Natureza, Área de Biologia, no Colégio de Aplicação - UFRGS. E-mail: rosane.garcia@ufrgs.br.

** Professora pesquisadora do Departamento de Expressão e Movimento, Área de Educação Física, no Colégio de Aplicação - UFRGS. E-mail: stelamaris24@gmail. com.

**** Professora pesquisadora do Departamento de Comunicação, Área de Língua Espanhola, no Colégio de Aplicação - UFRGS. E-mail: rosalia_lacerda@yahoo.com.br. 
se deter mais nos aspectos cognitivos e atitudinais do parecer.

Palavras-chave: Parecer descritivo; Avaliação; Projeto Amora; Ensino Fundamental.

\begin{abstract}
For some authors, the opinion descriptive is a form of descriptive evaluation records more qualified to describe the learning processes of students. However, others claim that so subjective reports and meaningless can be produced. The objectives of this study were check the level of understanding that parents and students have about the opinion descriptive prepared by teachers of that educational institution; acceptance of the content of the opinion with regard to attitudinal aspects, procedural and cognitive development of students. We used the questionnaires conducted qualitative analyzes and quantitative analyzes of opinions. The results showed that the opinion has great acceptance from parents and students, that the observations cognitive, attitudinal and procedural are addressed in balance and that those responsible for the students seem to hold more cognitive and attitudinal aspects of the opinion.
\end{abstract}

Keywords: Opinion descriptive; Evaluation; Projeto Amora; Basic Education.

\title{
Introdução
}

Esta pesquisa surgiu a partir das reflexões acerca de um estágio docente no Colégio de Aplicação (CAp) da UFRGS e norteou também um Trabalho de Conclusão de Curso, realizado no primeiro semestre de 2011.

A estagiária participou da elaboração de pareceres descritivos de estudantes da sexta série do Ensino Fundamental, utilizando como base as orientações para a observação e a avaliação do Projeto Amora (PA), do qual fazem parte as turmas de quinta 
e sexta séries. Também foi possível a estagiária acompanhar o Conselho de Professores, no qual os pareceres elaborados pelos tutores de cada estudante são discutidos por todos os docentes.

O Projeto Amora objetiva a reestruturação curricular, caracterizada pelos novos papéis do professor e do estudante, demandados pela construção compartilhada de conhecimentos, a partir de projetos de aprendizagem e da integração das tecnologias de informação e comunicação ao currículo escolar. $\mathrm{O}$ projeto atualmente envolve estudantes de $5^{\mathrm{a}}$ e $6^{\mathrm{a}}$ séries (ou $6^{\circ}$ e $7^{\circ}$ anos) do Ensino Fundamental do Colégio de Aplicação da UFRGS. Esse projeto está em funcionamento desde 1996 (Fonte: http:// www.ufrgs.br/projetoamora).

Durante o período de observações da estagiária, surgiu a dúvida sobre o quanto realmente os estudantes eram capazes de compreender os pareceres elaborados a seu respeito, o mesmo acontecendo em relação aos seus responsáveis. A investigação dessa questão é importante e coerente com os princípios do $\mathrm{PA}$, que procura fazer de sua práxis pedagógica um campo de investigação e de reflexão teórico-prática permanentes, além de valorizar a reflexão do estudante sobre sua própria aprendizagem (Projeto Amora, 2009).

Essa dúvida motivou mais indagações sobre os pareceres, o que levou a investigar também a aceitação pelo estudante do registro feito no parecer descritivo. Os estudantes do PA têm, em sua maioria, entre 11 e 12 anos de idade. Para Jean Piaget (s.d. apud OLIVEIRA, 1992, p. 12), essa faixa etária é caracterizada pela transição do período operatório concreto para o operatório formal, quando a criança tem a possibilidade de superar seu egocentrismo e passa a considerar o ponto de vista de outros como possível, articulando-os em seu raciocínio. Segundo Piaget (2002, p. 42), essa coordenação de pontos de vista se dá quando, por exemplo, é possível observar montanhas ou edifícios por meio de diferentes prismas, constituindo um todo articulado e significativo. Assim, existem estruturas operatórias estáveis que integram a base "concreta", elaborada nas etapas anteriores, e que permitem a estruturação das operações formais que estão agora desvinculadas 
do concreto, apoiando-se em hipóteses e não mais em objetos e em ações físicas. Com base nessas informações, era esperado encontrar níveis diferentes de receptividade aos pareceres entre os estudantes. Outra questão que motivou a presente pesquisa foi se o parecer se concentrava mais nos aspectos atitudinais ou nos relativos à aprendizagem do estudante.

Tendo em vista os aspectos gerais inicialmente expostos, o presente trabalho tem os seguintes objetivos:

a) verificar a compreensão que pais e estudantes consideram possuir do registro de avaliação;

b) descobrir de que maneira os estudantes significam o que é dito sobre eles e se os responsáveis concordam com o que é dito;

c) investigar a preferência de pais e de estudantes por notas ou por pareceres;

d) analisar a ênfase dada pelo parecer para os aspectos atitudinais e os cognitivos.

Atualmente, algumas instituições de ensino vêm modificando seu sistema de avaliação, substituindo a atribuição de notas e os cálculos de médias por conceitos e relatórios de acompanhamento (pareceres descritivos) do estudante. Essa forma de registro de avaliação é incentivada pela Lei de Diretrizes e Bases da Educação Nacional no 9.394/96 (p. 10), a qual estabelece, no Art. 24, que:

V - a verificação do rendimento escolar observará os seguintes critérios:

a) avaliação contínua e cumulativa do desempenho do estudante, com prevalência dos aspectos qualitativos sobre os quantitativos e dos resultados ao longo do período sobre os de eventuais provas finais; (BRASIL, 1996, p. 10).

Segundo Hoffmann (2010, p. 170), as escolas que ainda atribuem notas e médias aritméticas acabam cometendo dois equívocos: um deles é desconsiderar o caráter altamente subjetivo desses valores conferidos de forma arbitrária que podem ser injustos e genéricos. Outro é o de anular a visão sequencial, gradativa 
e de conjunto das aprendizagens construídas por educadores e educandos ao longo do processo. Por isso, quando é atribuída a um estudante uma nota insatisfatória, é possível dizer que esse não adquiriu conhecimentos necessários, porém não podemos dizer quais são esses e por qual motivo isso ocorreu.

No entanto, a adoção de pareceres descritivos ainda causa insegurança em alguns professores. Hoffmann (2009, p. 97) explica que essa postura é compreensível, já que os relatórios revelam o que melhor observamos, a forma como procedemos diante de determinadas questões, as posturas pedagógicas e os referenciais teóricos. Além disso, esses registros exigem exercício por parte dos educadores, sendo necessário prestarem atenção às manifestações dos estudantes, descrevê-las e refletir sobre elas de forma contínua.

Na opinião de Rosa (1997, p. 7), por melhores que sejam os pareceres, esses são incapazes de contemplar a riqueza de possibilidades de aprendizagem dos estudantes, sujeitos múltiplos, resultantes de diversas relações sociais prévias e paralelas à escola. Caso sejam elaborados sem alguns cuidados, os relatórios de acompanhamento podem ter pouco ou nenhum valor para os estudantes, por apresentar uma linguagem técnico-científica inacessível para os leigos, ideia postulada também por autoras como Hoffmann (2009) e Corazza (1995). Entretanto, a partir da experiência do PA, os docentes acreditam que é possível conceber uma avaliação por meio de pareceres descritivos que se expressa por meio de uma linguagem clara, evidenciando as aprendizagens e os possíveis entraves nesse processo. Acreditam também que ainda há a necessidade de criar estratégias para que os registros utilizados sejam compreendidos pelos estudantes, por seus responsáveis e por outros professores. É necessário criar espaços de discussão que promovam a reflexão acerca dos termos e dos conceitos que fazem parte do referencial e que embasam a elaboração dos pareceres descritivos, tornando essa linguagem corriqueira no dia a dia do trabalho escolar. Nesse sentido, é observado que, no PA, são organizados espaços para 
os esclarecimentos das categorias cognitivas que embasam e são utilizadas por todas as áreas do conhecimento na redação da avaliação dos estudantes; assim, cada professor explicita, em seus registros, seus critérios, que são integrados nesse processo. Cabe salientar que existe uma distinção importante entre o processo avaliativo que integra os diferentes registros, observações e instrumentos avaliativos, sistematizado, ao final do período de avaliação, no parecer descritivo.

Sobre as questões levantadas por Rosa (1997, p. 7), Hoffmann $(2009$, p. 101) defende a necessidade de elaborar pareceres que alcancem significado para os sujeitos aos quais se dirigem, tornando claros os referenciais teóricos que os sustentam.

Também é fundamental não se ater exclusivamente às questões atitudinais em detrimento das cognitivas, o que é muito observado em relatórios de avaliação e que pode transformar o parecer em um "catálogo escolar" de condutas, como relata Corazza (1995, p. 55):

Os textos 'prescritivos' dos pareceres ditos 'descritivos' corporificam um dos tantos instrumentos políticos de discriminação cultural utilizados pela escola em sua relação com os grupos sociais, ao se atribuir a força de legislar sobre quem é incluído e quem deve ser excluído; ao fabricar identidades pessoais e sociais; ao prescrever um catálogo de regulação moral para as posiçôes sociais e de sujeito admissíveis e inadmissíveis; ao criar e promover divisões de classe e gênero, inferiorizando e excluindo; enfim, ao moldar a armadura da conduta cotidiana escolar e os sujeitos que devem vesti-la. (CORAZZA, 1995, p. 55)

No entanto, os aspectos atitudinais e cognitivos não são independentes. No processo de avaliação do PA, os primeiros aspectos são abordados no parecer a partir do tipo de interação social que o estudante expressa por meio de suas condutas. Segundo Piaget (1994, p. 295), existe um paralelismo entre o desenvolvimento cognitivo e o moral que, no PA, é levado em consideração pelos professores no processo de avaliação, no sentido de conceber os princípios que regulam suas condutas e quais os processos cognitivos envolvidos; não para "moldar ou prescrever comportamentos", "formatando" sujeitos ou excluindo 
o caráter social. Para avaliar as interações sociais, é necessário atentar para o desenvolvimento moral. Para Piaget (1994, p. 155), nesse âmbito, existem dois estágios básicos, por meio dos quais o estudante transita em diferentes momentos da sua trajetória escolar: a heteronomia e a autonomia. $\mathrm{O}$ estudante tende para o primeiro estágio quando ele compreende as regras de maneira pouco flexível "ao pé da letra", as legitima a partir da obediência unilateral à autoridade, como uma referência concreta, ou seja, uma lei obrigatória ou agir de determinada maneira na presença do professor, por exemplo. Por outro lado, o estudante transita nos caminhos da autonomia, quando a regra é interiorizada e constitui-se por meio de princípios, ou seja, o estudante compreende o que baliza a própria criação da regra e o respeito se torna mútuo.

Segundo La Taille (1992, p. 65), o desenvolvimento da inteligência permite que o interesse do estudante que aprende possa ser despertado por um número cada vez maior de objetos e situações. Dessa maneira, acreditamos que tanto informações relacionadas à conduta quanto à aprendizagem são importantes para a elaboração de um parecer descritivo. Para La Taille (2006, p. 17), o desenvolvimento moral é interdependente de dois fatores: o desenvolvimento da inteligência, ou seja, requer a flexibilidade de pensamento, o que se torna possível por meio das operações; e é fruto de interações com o social, que, por sua vez, mobilizam aspectos endógenos nesse processo.

\section{Perspectiva de avaliação do Projeto Amora, segundo seus professores}

O PA busca, desde sua concepção, aproximar-se das ações realizadas pelo sujeito que conhece ou que se desenvolve, ao invés de apenas priorizar a transmissão que tem na linguagem seu principal instrumento. Dessa maneira, importa muito mais ao grupo de professores o que se faz (ações) com o que é lido/ 
ouvido/experimentado e não propriamente o que é transmitido pelo docente. Importa, portanto, não o comportamento ou a resposta padrão, mas a reconstituição e a transformação do vivido e do descoberto pelo sujeito. Nessa perspectiva, a linguagem não apenas representa a realidade, mas constitui, conserva e transforma aspectos da ação ou do pensamento, e isso tem valor de conhecimento (MACEDO, 1994, p. 18). Decorre dessa concepção, uma forma de avaliação que não prioriza instrumentos que têm na linguagem escrita sua referência de aprendizagem, como provas ou testes. O PA baseia sua avaliação em categorias cognitivas, propostas pelo autor Lino de Macedo (1994, p. 15), que argumenta:

Ao construtivismo interessam as ações do sujeito que conhece. Estas, organizadas enquanto esquemas de assimilação, possibilitam classificar, estabelecer relações, na ausência das quais aquilo que, por exemplo, se fala ou se escreve perde sentido (MACEDO, 1994, p. 15).

Dessa maneira, utilizam-se algumas categorias cognitivas, como a observação, a reconstituição, a antecipação, a explicação, a justificativa, a contraposição e a verificação (propostas por MACEDO 1994, p. 111), para descrever as ações e as operações dos estudantes em sala de aula.

\section{Delineamento metodológico}

\section{Questionários}

Para a investigação do nível de compreensão e de aceitação por parte de pais e estudantes, em relação ao registro da avaliação, foi realizada uma coleta de dados através de questionários dirigidos aos estudantes (Anexo I) e seus respectivos responsáveis (Anexo II) com perguntas abertas e fechadas.

Foram selecionados vinte estudantes, através de um sorteio, tomando-se o cuidado de obter o mesmo número de estudantes de quinta e de sexta séries. Aos questionários, foram anexados 
os Termos de Consentimento Informado e Esclarecido (Anexo III) para os responsáveis por cada estudante.

\section{Entrega dos questionários}

A entrega dos questionários e dos Termos de Consentimento Informado e Esclarecido foi feita aos pais ou aos responsáveis no momento da entrega de pareceres do segundo trimestre. Ao identificar que o responsável por um dos estudantes sorteados estava presente, os professores informavam quem ele era ao pesquisador, para que esse desse uma breve explicação a respeito da pesquisa e de seus objetivos. $\mathrm{O}$ pesquisador questionava ao responsável sobre seu interesse em participar. Neste mesmo dia, além da entrega dos pareceres, houve também uma apresentação de uma pesquisa feita pelos estudantes e uma palestra sobre desenvolvimento moral.

O momento da entrega de pareceres também é uma oportunidade que os pais possuem de esclarecer suas dúvidas sobre o mesmo e a situação escolar do estudante com os professores de todas as áreas do conhecimento.

Apenas quatorze dos vinte pareceres sorteados foram retirados neste dia e, portanto, somente quatorze Termos de Consentimento e questionários foram entregues aos pais. Desses, nove foram devolvidos pelos estudantes, sendo necessárias várias visitas às turmas para lembrá-los de trazer os Termos de Consentimento e os questionários respondidos pelos pais para que fosse possível aplicar o questionário nos estudantes. Tais documentos foram recolhidos em três dias diferentes. A entrevista dos estudantes somente foi realizada após a abordagem das dúvidas dos estudantes pelos professores sobre os pareceres, em uma das aulas de Articulação. 


\section{Observação da aula de articulação}

Após a entrega dos pareceres, os pais e os estudantes são orientados a lerem e a analisarem juntos o parecer, em casa. Posteriormente, os estudantes podem apresentar suas dúvidas sobre o parecer aos professores, em períodos de aula de Articulação.

Para esta pesquisa, foi feito um acompanhamento de um período de aula, em duas turmas diferentes, para observar o interesse dos estudantes em discutir essas questôes.

\section{Análise dos pareceres descritivos}

Nesta etapa da pesquisa, foi utilizado o método de análise documental, recorrendo à metodologia de análise de conteúdo (KRIPPENDORFF, 1980, p. 21 apud LÜDKE; ANDRÉ, 2012, p. 4l). Os pareceres descritivos elaborados pelos docentes do PA dos vinte estudantes sorteados foram analisados com o objetivo de classificar as frases em duas categorias: frases com ênfase em aspectos cognitivos e com ênfase em aspectos atitudinais e procedimentais. Este trabalho não visa ao estabelecimento de critérios e de um método de análise para diferenciar estas duas categorias, mas sim diagnosticar se um aspecto é mais favorecido do que o outro na redação dos pareceres.

Esta classificação mostrou-se mais complexa do que o esperado, já que várias frases tinham contribuição dos dois aspectos, sendo que às vezes aspectos atitudinais e procedimentais justificavam diagnósticos cognitivos. Por essa razão, foram introduzidas outras duas categorias: a de frases que englobam os três aspectos (com ambos componentes) e a de frases que não puderam ser classificadas.

Foram consideradas relativas a aspectos atitudinais todas as descrições que privilegiassem as questôes socioafetivas e de conduta do estudante, de acordo com a visão de Hoffmann (2009, p. 101). As descriçõos procedimentais foram reunidas aos aspectos atitudinais, formando uma mesma categoria. Já as 
relativas à aprendizagem, foram classificadas como referentes a aspectos cognitivos. A classificação em frases que englobam os três aspectos foi empregada quando as frases reuniam ambos os aspectos, como explicado anteriormente. A categoria de frases que não puderam ser classificadas foi utilizada quando não foi possível identificar ênfase em algum aspecto ou quando não se tornava muito claro a que o parecer se referia. A seguir, será apresentado um quadro (Quadro 1) com exemplo de como as frases dos pareceres foram separadas e analisadas.

Quadro 1: Exemplo de classificação completa de um dos pareceres descritivos

\begin{tabular}{|c|l|}
\hline $\begin{array}{l}\text { Classificação } \\
\text { das frases }\end{array}$ & Parecer número 1 \\
\hline $\begin{array}{l}\text { Atitudinais/ } \\
\text { procedimentais }\end{array}$ & $\begin{array}{l}\text { Na visão dos professores, * [1] mantém bom } \\
\text { relacionamento interpessoal com colegas e } \\
\text { professores. De modo geral, demonstra inte- } \\
\text { resse e comprometimento pelas aulas, uma vez } \\
\text { que entregou os trabalhos e temas solicitados. } \\
\text { E assídua e pontual. Mantém seu material } \\
\text { organizado (caderno, agenda e portfólio), } \\
\text { fazendo e atualizando registros das situações } \\
\text { de sala de aula. }\end{array}$ \\
\hline Cognitivas & $\begin{array}{l}\text { Sua produção oral e escrita evidencia que a } \\
\text { estudante reconstitui dados e fatos e estabelece } \\
\text { relações entre eles. }\end{array}$ \\
\hline $\begin{array}{c}\text { Atitudinais/ } \\
\text { procedimentais }\end{array}$ & $\begin{array}{l}\text { Participa das discussões em sala de aula, } \\
\text { mantém-se atenta e faz questionamentos aos } \\
\text { professores. }\end{array}$ \\
\hline
\end{tabular}




\begin{tabular}{|c|c|}
\hline Cognitivas & $\begin{array}{l}\text { É capaz de produzir hipóteses a respeito das } \\
\text { informações a que tem acesso, bem como de } \\
\text { compará-las com outras situaçôes que vivencia. } \\
\text { Consegue realizar uma observação geral dos } \\
\text { conteúdos e justifica fatos estabelecendo rela- } \\
\text { ções coerentes. Estabelece relações consistentes } \\
\text { entre os elementos que dispõe fazendo uso das } \\
\text { reconstituições de conceitos. }\end{array}$ \\
\hline $\begin{array}{l}\text { Atitudinais/ } \\
\text { procedimentais }\end{array}$ & $\begin{array}{l}\text { Realiza tanto atividades individuais quanto } \\
\text { coletivas de forma ordenada, colaborando } \\
\text { para o bom andamento da aula. A conversa, } \\
\text { em alguns momentos, a distrai, mas consegue } \\
\text { voltar para as atividades quando solicitado. Ao } \\
\text { final das aulas, contribui para a organização e } \\
\text { limpeza da sala ajudando colegas e professores } \\
\text { a deixar o espaço em condiçôes para ser usado } \\
\text { por outra turma. }\end{array}$ \\
\hline Cognitivas & $\begin{array}{l}\text { Sua produção escrita apresenta-se estruturada } \\
\text { adequadamente com divisão em parágrafos, } \\
\text { clareza, organização de ideias e poucas trocas } \\
\text { ortográficas. }\end{array}$ \\
\hline $\begin{array}{l}\text { Englobam os } \\
\text { três aspectos }\end{array}$ & $\begin{array}{l}\text { Em seu projeto de pesquisa, mostra-se interes- } \\
\text { sada pelo tema, demonstrando autonomia na } \\
\text { busca de informações, bem como uma produ- } \\
\text { ção escrita fluente e estruturada. }\end{array}$ \\
\hline Cognitivas & $\begin{array}{l}\text { Avança significativamente na leitura e aná- } \\
\text { lise das fontes, aprofundando seu trabalho. } \\
\text { Apropriou-se com qualidade da linguagem hi- } \\
\text { pertextual e faz uso de alguns recursos gráficos } \\
\text { e midiáticos para a apresentação dos resultados } \\
\text { parciais da pesquisa. }\end{array}$ \\
\hline $\begin{array}{l}\text { Atitudinais/ } \\
\text { procedimentais }\end{array}$ & $\begin{array}{l}\text { No grupo de projetos, verifica-se uma atitude } \\
\text { colaborativa, demonstrando disponibilidade } \\
\text { para ajudar os colegas. }\end{array}$ \\
\hline
\end{tabular}




\begin{tabular}{|l|l|}
\hline $\begin{array}{l}\text { Englobam os } \\
\text { três aspectos }\end{array}$ & $\begin{array}{l}\text { Mostrou interesse nas orientaçôes feitas pela } \\
\text { professora nos momentos de projeto de } \\
\text { aprendizagem, comprometimento e resultados } \\
\text { satisfatórios. }\end{array}$ \\
\hline $\begin{array}{l}\text { Que não } \\
\text { puderam ser } \\
\text { classificadas }\end{array}$ & $\begin{array}{l}\text { Submeteu seu projeto do segundo trimestre ao } \\
\text { UFRGS Jovem 2011. }\end{array}$ \\
\hline $\begin{array}{l}\text { Englobam os } \\
\text { três aspectos }\end{array}$ & $\begin{array}{l}\text { O Conselho de Professores reconhece os } \\
\text { esforços de } * \text { em ampliar sua produção nos } \\
\text { momentos de aprendizagem, bem como seu } \\
\text { envolvimento e o comprometimento em todas } \\
\text { as situações do Projeto Amora e confia nas } \\
\text { possibilidades de continuar qualificando seu } \\
\text { aprendizado }\end{array}$ \\
\hline
\end{tabular}

Fonte: Elaborado pelos autores.

Os pareceres puderam ser divididos em trechos que facilitaram a classificação. O primeiro parágrafo geralmente era referente ao relacionamento interpessoal do estudante com colegas e professores, à participação nas atividades, à organização dos materiais, à colaboração e ao atendimento a recomendaçôes dos professores. O segundo parágrafo tratava da qualidade das produçôes escritas, orais, corporais e expressivas, pontuadas de maneira conjunta - sem separações por área do conhecimento, por meio de categorias cognitivas que indicam a possibilidade e a qualidade das reconstituições dos conteúdos de maneira geral, das antecipações, do tipo de argumentação, do estabelecimento de relações entre conteúdos e a formulação de hipóteses. O terceiro parágrafo descrevia a participação do estudante nos Projetos de Investigação, podendo abordar tanto o envolvimento durante as atividades quanto a qualidade das suas produções. O quarto parágrafo reunia as recomendações dos professores para a melhoria do desempenho do estudante e do relacionamento interpessoal no ambiente escolar. 
Essa divisão evidencia o roteiro utilizado pelos professores para abordar tanto aspectos atitudinais e procedimentais quanto cognitivos (o documento Orientações para a observação dos estudantes e avaliação, conforme Anexo IV). Porém, nem sempre essa divisão foi tão homogênea, já que a redação final dos pareceres após o Conselho de Professores é feita pelos diferentes orientadores de cada estudante, que utilizam os dados e as informações registradas por todos os docentes numa planilha virtual (docs), preenchida para dar subsídios para a elaboração do parecer trimestral. Por meio dela, é possível conceber como se desenrolam os processos de construção de conhecimentos pautados pelas categorias cognitivas (MACEDO, 1994) explicadas anteriormente.

Para a classificação das frases, foi necessário separar os pareceres nessas quatro seçóes e analisar separadamente cada uma delas, para observar as semelhanças e as diferenças entre estudantes e, ainda, poder estabelecer os limites entre as categorias.

Depois de uma classificação preliminar, as recomendações dos professores foram analisadas, tendo em vista o parecer em sua totalidade para certificar se as mudanças sugeridas se tornaram necessárias, pelo fato de o estudante ter uma conduta considerada inadequada, ou por apresentar potencial de melhorar seu desempenho e suas produções.

Contudo, em algumas situações, nem com a leitura completa do parecer, as recomendações puderam ser classificadas com absoluta certeza em atitudinais, procedimentais ou cognitivas, sendo necessário agrupá-las como frases que não puderam ser classificadas. Um exemplo é a recomendação de que a família entre em contato com o NOPE (Núcleo de Orientação e Psicologia Educacional da escola), encaminhamento feito quando o estudante apresenta atitudes inadequadas no relacionamento com colegas e professores, ou quando possui desafios a serem vencidos nas questôes relativas à aprendizagem. Geralmente ambas eram relatadas nos pareceres com esta recomendação, não sendo possível dizer o motivo do encaminhamento. 
Após a classificação, as frases foram contadas. As classificadas englobando os três aspectos contribuíram para as categorias cognitivo e atitudinal/procedimental, sendo somadas a ambas. Já as frases que não puderam ser classificadas não contribuíram para nenhuma das categorias. Dessa maneira, para um parecer com cinco frases de caráter atitudinal/procedimental, seis de cognitivo, três que englobam os três aspectos e uma que não pode ser classificada, as frases que englobam os três aspectos eram somadas às categorias atitudinal/procedimental e cognitiva obtendo: oito atitudinais/procedimentais, nove cognitivas e uma que não pode ser classificada. Em seguida, o número total de frases de cada categoria (categoria atitudinal/procedimental e categoria cognitiva) foi somado e foi calculada a média das mesmas, com a finalidade de verificar se os professores privilegiam um tipo de informação ou se estas são abordadas na mesma proporção em seus relatos.

\section{Resultados e discussão}

\section{Questionário direcionado aos estudantes}

O perfil dos nove estudantes que responderam ao questionário é mostrado nos gráficos a seguir (Figura 1 ).

Figura 1: Perfil dos estudantes que responderam o questionário.

Sexo

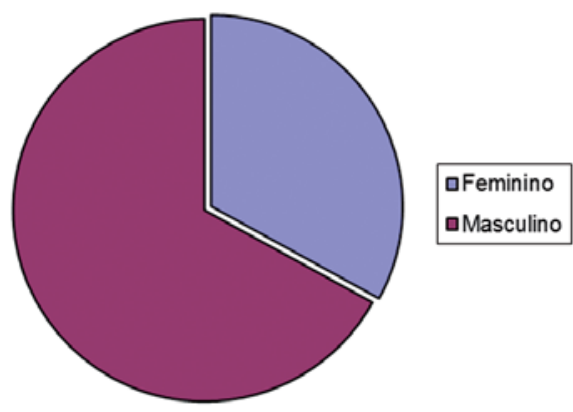


Idade (anos)

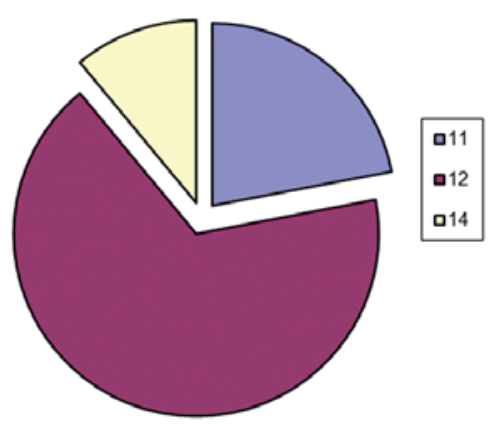

Fonte: Elaborada pelos autores.

\section{Sobre a aceitação das representações feitas pelo parecer}

Nenhum dos estudantes afirmou acreditar que o parecer apresenta descriçóes de sua conduta ou do seu aprendizado que sejam injustas ou que não condizem com a realidade. Como pode ser observado nas suas respostas:

- "O que entendo/acho justo".

- "Eu acho que os professores falam bem de mim no parecer, apesar de eu gostar de ler".

- "No parecer é escrito que eu tenho um comportamento bom, mas que eu tenho que melhorar a conversa e a atenção".

- "Eu acho justo".

- "Acho que a avaliação foi justa sim porque eu já sabia o que eu fazia e não fazia na aula".

- "Acho que é justo porque eu faço o que eles botaram".

- "Como eu estou na escola, eu acho justo". 
- "Sim, acho justo, pois todos os professores escrevem a sua opinião sobre mim”.

- "Eu acho que de vez em quando é meio exagerado o que eles falam sobre mim".

Apenas um estudante afirmou que às vezes o que é dito é "meio exagerado", o que indica que as informações contidas no parecer têm uma boa aceitação por parte dos estudantes.

\section{Sobre a percepção do nível de compreensão}

A maioria dos estudantes afirmou compreender tudo o que é dito no parecer (78\%). Um estudante afirmou entender algumas partes do parecer, mas outras não (11\%). Outra estudante afirmou não compreender nada do parecer (11\%).

Ao explicar o que não compreendia do parecer, a estudante diz: "Não entendo se estou bem nas matérias, se estou entendendo". Acreditamos que este relato possa ser explicado por um interesse da estudante de compreender seu desempenho em cada área do conhecimento.

Na observação da aula de Articulação, em que os estudantes fizeram a exposição de suas dúvidas sobre o parecer, foram verificados níveis de interesse muito contrastantes entre as duas turmas. Na turma de quinta série, a professora não conseguiu a colaboração dos estudantes, pois esses conversavam muito, não contribuíam com questionamentos e realizavam atividades não relacionadas com a aula. Já na turma de sexta série, os professores conseguiram abordar o significado de termos como reconstituição e antonomia; como eram avaliadas as condutas sociais e a organização; as possibilidades cognitivas; a produção escrita, oral, corporal e artística, tudo isso com grandes contribuições dos estudantes.

É importante observar que a estudante que relatou não compreender o parecer faz parte da turma que mais interagiu com 
os professores, o que pode indicar que o motivo da afirmação é realmente a ausência de informaçôes específicas para cada área do conhecimento e não por haver falta de clareza nas descrições apresentadas no parecer.

\section{Sobre a preferência dos estudantes por notas ou pareceres}

Apenas um estudante (11\%) disse ter preferência por pareceres como forma de registro de avaliação. Um estudante afirma preferir somente notas (11\%) e outros sete afirmam ter interesse pelos dois em conjunto $(78 \%)$.

O estudante que disse preferir os pareceres sempre estudou no Colégio de Aplicação e foi avaliado através de pareceres. O estudante que manifestou maior interesse pelas notas foi avaliado dessa maneira em outras escolas. Dos sete estudantes restantes, que afirmaram preferir os dois registros em conjunto, três foram avaliados através de notas em outra escola e quatro somente através de parecer descritivo.

Talvez o interesse pelas notas esteja relacionado com as experiências anteriores dos estudantes com este registro de avaliação. Esse dado parece interessante para futuras investigações que visem a analisar a influência de experiências anteriores dos estudantes com outros registros de avaliação na vida escolar em outras instituições de ensino. É possível pensar que ambos os registros de avaliação sejam subjetivos. Entretanto, existe a possibilidade de que os estudantes acreditem que, em conjunto, o parecer e a nota podem mostrar de uma maneira mais clara o seu desempenho, sendo a nota talvez uma medida mais concreta na concepção do estudante. 


\section{Questionário direcionado aos pais ou responsáveis}

\section{Sobre os aspectos mais observados pelos pais no parecer}

A questão de número quatro foi interpretada pelos pais de maneira diferente da esperada. Ela acabou revelando se os pais se detêm mais nas informações relativas ao comportamento, ou ao aprendizado do estudante e não a opinião desses sobre a representação feita no parecer. A análise dessa questão foi sendo feita na medida em que os questionários eram entregues e nossa percepção inicial era a de que os pais pareciam perceber mais a descrição do comportamento do estudante. No entanto, com a análise de todos os nove questionários, não podemos afirmar que os pais detenham maior atenção aos aspectos atitudinais.

Três das respostas não revelam quais aspectos são mais bem observados:

- "Eu gosto e demonstram que realmente observam o estudante num contexto geral, apesar das observações acima".

- "Entendo e assim podemos refletir em família potencializando coisas boas e melhorando coisas não tão boas. Acredito que tudo é possível reavaliar".

- "Achamos que na maioria dos pareceres, ou melhor, todos eles descrevem o que ele tem que melhorar, e que está desenvolvendo bem".

Uma das respostas evidencia mais atenção aos aspectos atitudinais e procedimentais:

- "Está coerente com a realidade dele, pois ele é o mesmo em casa. Meio desorganizado e desatento".

As outras cinco respostas mostram que os aspectos cognitivos são observados, podendo fazer também menção aos atitudinais e procedimentais: 
- "Que minha filha melhorou o comportamento, e está mais concentrada nas atividades escolares, conversar menos e ter mais aprofundamento em produção de texto".

- "Pelo que eu entendi ele fica de folia na sala de aula atrapalhando os colegas. Que ele tem que ler e escrever e corrigir e que ele precisa ajuda em matemática”.

- "Acho que corresponde ao aprendizado dele, principalmente sobre as dificuldades".

- "Gosto muito. Estou muito satisfeita com o desenvolvimento de minha filha".

- "Na minha compreensão entendo que em algumas matérias ele se identifica melhor e assim se aprofunda e se interessa mais do que as outras, e acho perfeitamente normal. Mas sei que ele tem que estudar e se dedicar em todas elas”.

\section{Sobre a percepção do nível de compreensão}

A maioria dos responsáveis afirmou compreender tudo que é dito no parecer descritivo (78\%), sendo que o restante disse compreender algumas partes e outras não $(22 \%)$.

A questão três esclarece que os termos técnico-científicos são a razão da dificuldade de compreensão relatada, como é evidenciado pela resposta: "Alguns termos técnicos e em alguns trechos é repetitivo". Outra das respostas ainda fornece um trecho de parecer: "O estudante faz reconstituições aprofundadas sobre texto e leitura, mas em alguns momentos reconstitui conceitos de forma ainda artificial sobre os conteúdos estudados?”. Essas afirmações foram apresentadas por pais com Ensino Médio completo (22\%). O restante dos pais, que afirmou compreender todo o parecer, foi formado por $11 \%$ com Ensino Fundamental incompleto, 22\% com Médio incompleto, e 44\% com Ensino Superior. 
É possível que a compreensão desse trecho especificamente tenha sido dificultada tanto pelos termos técnicos quanto pelo caráter subjetivo do termo "artificial". Isso é consistente com as observações de Rosa (1997) e outras autoras, como mencionado anteriormente. Em discussão posterior acerca do termo "artificial", foi esclarecido com os professores que esta palavra não é normalmente utilizada na elaboração dos pareceres. As mais utilizadas, no contexto apresentado anteriormente, seriam: "superficial" ou "parcial"; nesse sentido, acreditamos que houve falta de entendimento na leitura ou erro de digitação no parecer. Os professores ponderaram, também, que esse é um exemplo de situação que pode ocorrer e que, por si, constitui um desafio para o processo avaliativo. Com o objetivo de evitar mal entendidos, explicitando as ideias da maneira mais adequada para estudantes e seus responsáveis, têm sido implementadas ações na dinâmica do próprio currículo do PA para esclarecer a linguagem, o vocabulário e os conceitos empregados, tanto na avaliação como no cotidiano dos professores. Um desses momentos já foi descrito anteriormente na aula de Articulação.

\section{Sobre a preferência dos pais por notas ou pareceres}

A maioria dos pais relata a preferência pelos dois registros de resultados em conjunto (78\%), enquanto o restante afirma preferir apenas o registro atual $(22 \%)$.

Os pais que disseram preferir somente o parecer tiveram apenas experiências anteriores com este tipo de avaliação, no próprio CAp. Dos que manifestam interesse pelos dois registros, três não tiveram contato com avaliação através de notas e quatro foram avaliados dessa maneira em outras escolas. Talvez esse interesse pelas notas esteja relacionado com as experiências anteriores dos pais com o método utilizado para avaliar seus filhos, assim como o dos estudantes, discutidos anteriormente neste trabalho. 
Dois dos pais relatam sentir falta de informações a respeito do desempenho do estudante nas diferentes disciplinas. Como evidenciado pelas respostas:

- "Meu filho apresenta algumas dificuldades de aprendizagem, isto é relatado de forma clara no que se refere à produção escrita. Quanto aos outros componentes (História, Geografia, Ciências, Matemática...) não tenho informações, pois raras vezes as avaliações são devolvidas ao estudante. Muitos professores trabalham de forma diferenciada, utilizando vários recursos isto é positivo, entretanto, não fica claro para a família o assunto que está sendo estudado, pois não vem registro para casa”.

- "Acho que poderiam expressar opiniões a respeito de outras disciplinas, pois normalmente é sobre relacionamento com os colegas e sobre Língua Portuguesa”.

Todavia, não é possível relacionar a necessidade sentida pelos pais de mais informaçôes com a preferência pelos dois instrumentos de apresentação de resultados, já que um dos pais afirma preferir somente o parecer. Dos sete pais que afirmaram a preferência pelos dois instrumentos, quatro dizem que o parecer é completo, não sendo necessário adicionar informações, um diz sentir falta da nota na avaliação, um afirma serem necessárias mais informaçôes sobre o desenvolvimento cognitivo em outras disciplinas e um solicita mais recomendações aos pais para auxiliar o estudante, como relatado na resposta a seguir:

- "De que modo nós, pais, podemos reagir, para ajudá-lo a melhorar nos estudos e ter mais interesse?".

É possível que o desejo dos pais pela nota não esteja relacionado com uma falta de mais informações sobre o desempenho do estudante. Portanto, é necessário verificar se esta preferência é realmente influenciada pelas experiências anteriores com avaliação através de notas. 


\section{Análise da predominância de aspectos atitudinais/procedimentais ou cognitivos}

No quadro abaixo (Quadro 2), estão apresentados os resultados das análises referentes ao número de frases de cada categoria nos pareceres analisados.

Quadro 2: Número de frases em cada categoria em cada um dos pareceres.

\begin{tabular}{|c|c|c|c|c|c|}
\hline \multirow[b]{2}{*}{$\begin{array}{l}\text { Parecer } \\
\text { número }\end{array}$} & \multicolumn{5}{|c|}{ Número de frases } \\
\hline & $\begin{array}{l}\text { Atitudinais/ } \\
\text { Procedimentais }\end{array}$ & Cognitivas & $\begin{array}{l}\text { Englobam } \\
\text { os três } \\
\text { aspectos }\end{array}$ & $\begin{array}{l}\text { Que não } \\
\text { puderam ser } \\
\text { classificadas }\end{array}$ & Total \\
\hline 1 & 9 & 7 & 3 & 1 & 20 \\
\hline 2 & 5 & 4 & 2 & l & 12 \\
\hline 3 & 8 & 6 & 3 & 1 & 18 \\
\hline 4 & 7 & 8 & 2 & 0 & 17 \\
\hline 5 & 8 & 5 & 0 & 1 & 14 \\
\hline 6 & 9 & 5 & 0 & 3 & 17 \\
\hline 7 & 4 & 10 & 5 & 3 & 22 \\
\hline 8 & 7 & 6 & 2 & 1 & 16 \\
\hline 9 & 10 & 6 & 2 & 1 & 19 \\
\hline 10 & 8 & 9 & 1 & 2 & 20 \\
\hline 11 & 7 & 10 & 2 & 2 & 21 \\
\hline 12 & 4 & 8 & 0 & 2 & 14 \\
\hline 13 & 5 & 13 & 2 & 2 & 22 \\
\hline 14 & 6 & 7 & 0 & 1 & 14 \\
\hline
\end{tabular}




\begin{tabular}{|l|l|l|l|l|l|}
\hline 15 & 7 & 5 & 2 & 0 & 14 \\
\hline 16 & 9 & 3 & 1 & 0 & 13 \\
\hline 17 & 3 & 4 & 2 & 3 & 12 \\
\hline 18 & 6 & 5 & 4 & 2 & 17 \\
\hline 19 & 8 & 5 & 3 & 1 & 17 \\
\hline 20 & 7 & 6 & 2 & 1 & 16 \\
\hline
\end{tabular}

Fonte: Elaborado pelos autores.

As médias do número de frases foram de 8,5 para a categoria cognitivo e de 8,75 para a atitudinal/procedimental. Foram utilizadas pelos professores apenas cinco frases a mais para descrever os aspectos atitudinais/procedimentais dos estudantes do que para os aspectos cognitivos. As médias são muito próximas $\mathrm{e}$, por isso, acreditamos que os professores parecem descrever os aspectos atitudinais e procedimentais na mesma medida em que os aspectos cognitivos, não privilegiando um tipo de informação (Quadro 3 e Figura 2).

Quadro 3: Frequências e médias totais de cada categoria de frases dos pareceres descritivos.

\begin{tabular}{|l|l|l|}
\hline Características predominantes & Frequência total & Média \\
\hline Atitudinais/ procedimentais & 137 & 6,85 \\
\hline Cognitivas & 132 & 6,6 \\
\hline Englobam os três aspectos & 38 & 1,9 \\
\hline Que não puderam ser classificadas & 28 & 1,4 \\
\hline $\begin{array}{l}\text { Atitudinais/procedimentais e que } \\
\text { englobam os três aspectos }\end{array}$ & 175 & 8,75 \\
\hline $\begin{array}{l}\text { Cognitivas e que englobam os } \\
\text { três aspectos }\end{array}$ & 170 & 8,5 \\
\hline Total de frases & 335 & \\
\hline
\end{tabular}

Fonte: Elaborado pelos autores. 
Figura 2: Gráfico com a frequência das frases em cada categoria dos pareceres descritivos.

Frequência
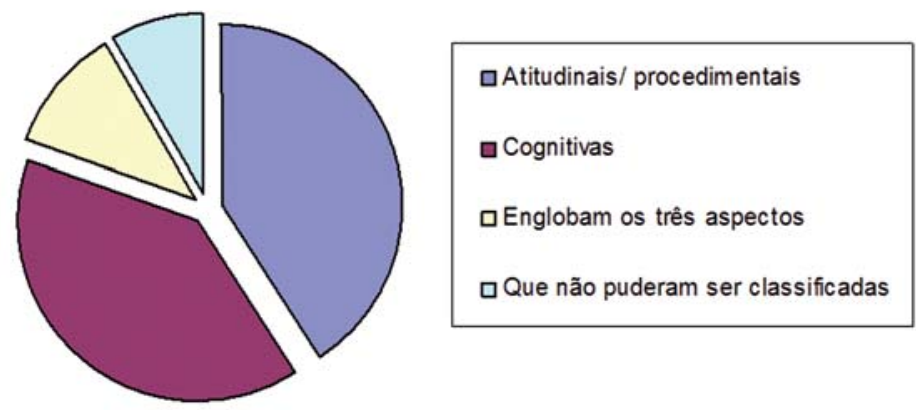

Fonte: Elaborada pelos autores.

Os docentes relataram pessoalmente que a turma de quinta série apresenta mais problemas disciplinares, sendo necessárias várias intervenções, diferentemente das turmas de sexta série. É importante observar que a diferença de idade entre os estudantes de quinta e de sexta séries é muito pequena, sendo a média de idades 12,2 anos na turma de quinta série (Amora 1) e 12,6 anos nas turmas de sexta série (Amora 2). Com base nessa informação, foram comparadas as frequências dos pareceres também separadamente, a fim de verificar se as descriçóes evidenciavam a diferença relatada pelos professores, trazendo possivelmente, mais descrições atitudinais e procedimentais do que cognitivas (Quadro 4). Novamente, os resultados mostraram um equilíbrio entre as duas descrições. 
Quadro 4: Frequências e médias para cada série.

\begin{tabular}{|l|l|l|l|l|}
\cline { 2 - 5 } \multicolumn{1}{c|}{} & \multicolumn{2}{|l|}{ Atitudinal e procedimental } & \multicolumn{2}{l|}{ Cognitivo } \\
\cline { 2 - 5 } \multicolumn{1}{c|}{} & Frequência & Média & Frequência & Média \\
\hline Amora 1 & 87 & 8,7 & 84 & 8,4 \\
\hline Amora 2 & 88 & 8,8 & 86 & 8,6 \\
\hline
\end{tabular}

Fonte: Elaborado pelos autores.

É possível que o equilíbrio entre a frequência das frases referentes aos aspectos cognitivos e das que abordam aspectos atitudinais e procedimentais, esteja evidenciando os referenciais teóricos nos quais o PA se baseia (PROJETO AMORA, 2009).

\section{Considerações finais}

Os dados apresentados nesta pesquisa demonstram que os pareceres produzidos no PA são capazes de ser compreendidos tanto pelos estudantes quanto pelos seus responsáveis. Os resultados evidenciam que há a compreensão de ambos com relação às informações e uma aceitação pelos estudantes do que é dito sobre eles, mesmo nestes registros de avaliação. As falas dos estudantes mostram que o ponto de vista dos outros é considerado e essa é uma das características do período de desenvolvimento operatório formal, como explicado anteriormente (PIAGET, 2002 , p. 47). É observado que estabelecem relações entre o que é expresso no registro de avaliação e a sua vida escolar. No entanto, seriam necessários outros estudos para conceber a abrangência dessas significações e o caráter de desenvolvimento moral expresso por elas.

O diagnóstico de que tanto pais quanto estudantes têm interesse na inclusão de notas na avaliação deve ser analisado mais a fundo. Quais são as razões para esse interesse? Com base nos questionários respondidos por pais e estudantes, é possível verificar que isso não está relacionado com uma provável falta de 
informações sobre o desempenho e desenvolvimento do estudante. Talvez esse interesse seja motivado por experiências anteriores com as notas, mas não é possível apresentar esta conclusão sem entrevistar um número maior de pais e estudantes, com perguntas mais diretas sobre essa questão. A adoção de uma avaliação por meio de notas não é coerente com os referenciais teóricos do PA (2009), que valoriza uma reflexão contínua sobre o que o estudante aprende, o caminho percorrido durante seu aprendizado e o desenvolvimento de várias habilidades que não podem ser expressas através de um número. Contudo, seriam necessárias outras investigações para conceber as aproximações e os distanciamentos entre os dois modelos. Outro aspecto interessante seria estabelecer relações entre o que uma maneira de avaliar e outra promovem no tipo de representação do estudante que ingressa no mercado de trabalho ou na universidade, pois, nesses âmbitos, na maioria das vezes, são utilizados modelos avaliativos quantitativos.

No Conselho de Professores (conhecido, em outras escolas, como Conselho de Classe), é possível perceber o quanto a produção dos pareceres exige tempo e dedicação dos docentes. Os professores relatam que o esforço feito por eles na elaboração muitas vezes não é valorizado pelos pais. Muitos deles não compareceram à entrega dos pareceres do segundo trimestre, na qual outras atividades esclarecedoras sobre os estudantes e seu desenvolvimento fizeram parte do planejamento. Sobre a influência dos pais na escola, Hoffmann (2001, p. 49) afirma que promover o diálogo com as famílias não significa compartilhar com elas o compromisso profissional da escola. Para a autora, decisões sobre a forma de apresentação dos resultados não devem ser feitas pelos pais, já que esses não possuem as mesmas competências profissionais que os docentes. No entanto, afirma que a escola precisa explicar seus princípios e fundamentos ao escolher seus instrumentos metodológicos de acompanhamento do estudante, o que está ao alcance dos pais em várias oportunidades criadas pelo PA. 
Mesmo levando em conta dados obtidos acerca do equilíbrio encontrado entre os aspectos cognitivos e atitudinais na avaliação que ocorre no PA, é importante ressaltar que, ao eleger o parecer descritivo como um instrumento de apresentação de resultados capaz de explicar com mais detalhes o desenvolvimento do estudante, muitos professores, em muitas escolas, ainda correm o risco de se aterem exclusivamente a questões atitudinais. Tais documentos, segundo Corazza (1995, p. 55), acabam tendo efeitos homogeneizadores, discriminatórios e excludentes, além de estabelecer parâmetros para julgar o que seria uma boa ou má criança. Mello (1985 apud HOFFMANN, 2009, p. 102) descreve que dificilmente tais explicações questionam a ação da escola, dando a impressão de que o repertório de condutas adequadas à aprendizagem constitui algo que deve estar pronto e acabado antes e independentemente da experiência escolar. Os docentes do PA compreendem que as condutas não são independentes da experiência escolar e que essas se modificam durante o desenvolvimento cognitivo. Isso é evidenciado pelos referenciais teóricos que embasam o Projeto. É possível destacar o interacionismo de Piaget, segundo o qual as principais etapas das operações lógicas, correspondem a estágios correlativos de desenvolvimento social. Para Piaget (1967 apud LA TAILLE, 1992, p. 11), a inteligência humana somente desenvolve-se no indivíduo em função de interações sociais que são, em geral, demasiadamente negligenciadas.

Por fim, é evidenciado nesta pesquisa que os docentes do $\mathrm{PA}$ não privilegiam os aspectos atitudinais e procedimentais em relação aos cognitivos ao redigir os pareceres e fazem uso de ambas as descrições em quantidades muito semelhantes, o que está de acordo com os referenciais teóricos adotados pelo projeto. Da mesma maneira que os docentes, os pais parecem ter o cuidado de observar tanto aspectos atitudinais quanto cognitivos ao fazer a leitura do registro de avaliação. Nesse sentido, acredita-se que refletir e definir referenciais teóricos condizentes com os objetivos 
da avaliação seja essencial para produzir pareceres capazes de contemplar de maneira coerente e significativa o desenvolvimento e as potencialidades dos estudantes.

\section{Referências}

BRASIL. Ministério da Educação. Lei no 9.394 de 20 de dezembro de 1996. Brasília, 1996. Disponível em: http://www.planalto.gov.br/ ccivil_03/Leis/L9394.htm. Acesso em 23 nov. 2011.

CORAZZA, Sandra Mara. Currículo e política cultural da avaliação. Educação e Realidade. Porto Alegre: Faced/UFRGS, v. 20, n. 2, p. 47-59, jul./dez. 1995.

HOFFMANN, Jussara Maria Lerch. Avaliar para promover: as setas do caminho. Porto Alegre: Mediação, 2001.

. Avaliação mediadora: uma prática em construção da pré-escola à universidade. Porto Alegre: Mediação, 2009.

- Avaliar: respeitar primeiro, educar depois. Porto Alegre: Mediação, 2010.

KRIPPENDORFF, Klaus. “Content Analysis”. Beverly Hills, Ca., SAGE, 1980 apud LÜDKE, Menga; ANDRÉ, Marli Eliza Dalmazo Afonso de. Pesquisa em Educação: abordagens qualitativas. [Reimpr.] São Paulo, E. P. U., 2012.

LA TAILLE, Yves de. Desenvolvimento do juízo moral e afetividade na teoria de Jean Piaget. In: LA TAILLE, Yves de; OLIVEIRA, Marta Kohl de; DANTAS, Heloysa. Piaget, Vygotsky, Wallon: Teorias psicogenéticas em discussão. São Paulo: Summus, 1992. p. 47-73.

. O lugar da interação social na concepção de Jean Piaget. In: LA TAILlE, Yves de; OLIVEIRA, Marta Kohl de; DANTAS, Heloysa. Piaget, Vygotsky, Wallon: Teorias psicogenéticas em discussão. São Paulo: Summus, 1992. p. 11-21. 
. Moral e ética: dimensões intelectuais e afetivas. Porto Alegre: Artmed, 2006.

MACEDO, Lino de. Ensaios construtivistas. São Paulo: Casa do Psicólogo, 1994.

OLIVEIRA, Daisy Lara de. O antropocentrismo no ensino de ciências. Espaços da escola. Ijuí: UNIJUÍ. v. 1, n. 4, p. 8-15, abr./jun. 1992.

PIAGET, Jean. Estudos sociológicos. Rio de Janeiro: Editora Forense, 1973. . O juízo moral na criança. São Paulo: Summus, 1994. . Epistemologia genética. São Paulo: Martins Fontes, 2002.

PROJETO AMORA 2009/2010. Universidade Federal do Rio Grande do Sul, Colégio de Aplicação, 2009, 16 p. Disponível em: <http://paginas. ufrgs.br/projetoamora/documentos/textos/projeto_amora20092010.doc/ view $>$ Acesso em 13 dez. 2011.

ROSA, Russel Teresinha Dutra da. Algumas discussões envolvendo processos de avaliação. Espaços da Escola. Ijuí: UNIJUÍ , v. 4 , n. 25, jul./set. 1997. p. 5-18. 